\title{
RECONFIGURAÇÕES PROFISSIONAIS EM CONTEXTOS \\ DE MUDANÇA O papel da medicina geral e familiar
}

\author{
Hélder Raposo \\ H\&TRC, Centro de Investigação em Saúde e Tecnologia, Escola Superior de Tecnologia da Saúde \\ de Lisboa, Lisboa, Portugal \\ Centro de Investigação e Estudos de Sociologia (ISCTE-IUL), Lisboa, Portugal
}

Resumo No atual enquadramento regulatório das políticas públicas de saúde verifica-se um maior escrutínio público sobre a medicina, pelo que os atores institucionais se têm empenhado na implementação de medidas que procuram reduzir a variação das práticas médicas, concretamente através das chamadas normas de orientação clínica (NOC). Considerando o processo formal da sua implementação em Portugal, o objetivo específico deste artigo é explorar as razões que explicam a adesão a esta lógica de padronização por parte da medicina geral e familiar (MGF). No quadro de uma metodologia qualitativa-intensiva mais ampla, são aqui mobilizados os resultados empíricos decorrentes da aplicação de um conjunto de entrevistas semiestruturadas junto de um número restrito de informantes privilegiados acerca do envolvimento da MGF neste processo, bem como um suporte documental específico enquadrador da sua implementação em Portugal. Constata-se que a vulnerabilidade deste segmento profissional às interferências regulatórias que foram desencadeadas acabou por ser contingente, dado que a concretização do processo de implementação das NOC implicou uma lógica de negociação que assegurou a participação dos profissionais na própria modulação desta iniciativa e constituiu-se como uma oportunidade de reforço da afirmação profissional desta especialidade médica.

Palavras-chave: padronização, profissão médica, normas de orientação clínica (NOC), medicina geral e familiar (MGF).

Abstract In the current regulatory framework of public health policies there is a greater public scrutiny upon medicine, and institutional actors have been engaged in the implementation of measures that seek to link professional interventions to the demonstration of their effectiveness and efficiency, namely through the so-called clinical guidelines. Considering the formal process of its implementation in Portugal, the aim of this article is to explore the reasons why general practice adheres to this standardization logic. Within the framework of a broader qualitative-intensive methodology, we present the empirical results obtained from the application of a set of semi-structured interviews with a limited number of privileged informants about the involvement of general practice in this process, as well as specific documentary support about its implementation in Portugal. The vulnerability of this professional segment to regulatory interference that has been triggered proved to be contingent, since the implementation of the clinical guidelines process implied a negotiation logic that ensured the participation of professionals in the modulation of this initiative itself and constituted an opportunity to reinforce the professionalization of this medical specialty.

Keywords: standardization, medical profession, clinical guidelines, general practice.

Résumé Dans l'actuel encadrement régulateur des politiques publiques de santé s'est vérifiée une plus grande surveillance publique sur la médicine, d'où un engagement des acteurs institutionnels dans l'implémentation de mesures qui cherchent à réduire la variation des pratiques médicinales à travers les dénommées normes d'orientation clinique. En tenant compte du processus formel de son implémentation au Portugal, l'objectif spécifique de cet article est celui d'explorer les raisons qui expliquent l'adhésion à cette logique de standardisation de la médicine générale. Dans le cadre d'une méthodologie qualitative et intensive, sont présentés les résultats empiriques obtenus par l'application d'un ensemble d'entretiens semi-structurés avec un nombre limité d'informateurs privilégiés sur l'implication des médecines générales dans ce processus, ainsi qu'un support documentaire spécifique sur sa mise en œuvre au Portugal. On constate que la vulnérabilité de ce segment professionnel aux interférences réglementaires déclenchées s'est révélée contingent, étant donné que la concrétisation de ce processus de mise en œuvre de normes d'orientation clinique a impliqué une logique de négociation, qui a assuré la participation des professionnels dans la propre modulation de cette initiative et, s'est ainsi constituée comme une opportunité de consolidation de l'affirmation professionnelle de cette spécialité médicale.

Mots-clé: standardisation, profession médicale, normes d'orientation clinique, médecine générale. 
Résumé En el actual encuadre regulatorio de las políticas públicas de salud se verifica un mayor escrutinio público sobre la medicina, por lo que los actores institucionales se han empeñado en la implementación de medidas que buscan reducir la variación de las prácticas médicas, concretamente a través de las llamadas normas de orientación clínica (NOC). Considerando el proceso formal de su implementación en Portugal, el objetivo específico de este artículo es explorar las razones que explican la adhesión a esta lógica de estandarización por parte de la medicina general y familiar (MGF). En el contexto de una metodología cualitativa-intensiva más amplia, están aquí movilizados los resultados empíricos derivados de la aplicación de un conjunto de entrevistas semi-estructuradas junto de un número restringido de informantes privilegiados acerca de la implicación de la MGF en este proceso, así como un soporte documental específico de su implementación en Portugal. Se constata que la vulnerabilidad de este segmento profesional a las interferencias regulatorias que fueron desencadenadas acabó por ser contingente, dado que la concretización del proceso de implementación de las NOC implicó una lógica de negociación que aseguró la participación de los profesionales en la propia modulación de esta iniciativa y se constituye como una oportunidad de refuerzo de la afirmación profesional de esta especialidad médica.

Palabras-clave: estandarización, profesión médica, normas de orientación clínica (NOC), medicina general y familiar (MGF).

\section{Introdução}

No atual panorama de um maior escrutínio público sobre a medicina, os atores institucionais com responsabilidades regulatórias no campo da saúde têm-se empenhado na implementação de princípios organizacionais que procuram vincular as intervenções profissionais à demonstração da sua eficácia e eficiência. O pressuposto é que a diversidade das práticas médicas é um obstáculo à difusão de critérios de eficiência e de qualidade assistencial, o que se traduz no argumento de que os "tradicionais" mecanismos de autorregulação da medicina não são satisfatórios para assegurar a implementação deste tipo de mudanças. No âmbito destas orientações políticas no campo da saúde, preconiza-se, por conseguinte, que os profissionais da medicina devem passar a ser objeto de critérios de prestação de contas.

À luz deste entendimento, torna-se imperativo o objetivo de desenvolver e implementar mecanismos que assegurem práticas mais padronizadas na prestação dos cuidados de saúde, pelo que têm sido amplamente disseminados vários instrumentos formais que visam conferir um reforço da consistência científica das práticas médicas e da previsibilidade das suas intervenções, destacando-se neste âmbito as chamadas normas de orientação clínica (NOC). As NOC consistem, assim, em instrumentos que traduzem para a prática médica a evidência científica decorrente da investigação clínica e constituem-se como recomendações sistematizadas para apoiar as decisões médicas para as várias circunstâncias clínicas específicas.

Ora sendo a medicina de um caso paradigmático de uma profissão cuja institucionalização se traduziu historicamente na capacidade de conversão dos seus conhecimentos específicos e saberes profissionais em formas organizadas de poder que asseguram um espaço de pericialidade protegido das interferências externas de outros grupos e atores (Freidson, 1988 [1970]; Larson, 2013 [1977]; Starr, 1982; Carapinheiro, 1993; Serra, 2008), compreende-se que o caráter específico e distintivo do seu conhecimento seja especialmente mobilizado como um importante recurso na defesa da sua jurisdição (Abbot, 1988). É precisamente por esta razão que as recentes 
dinâmicas de desenvolvimento de instrumentos formalizados como as NOC acabam, não apenas por entrar numa relação de potencial tensão com a valorização da autonomia profissional e clínica (Freidson, 1988 [1970]), mas também acabam por comprometer as caraterísticas do anterior modelo colegial que caraterizou a trajetória de afirmação da autoridade pericial e da legitimidade cultural da profissão médica, designadamente no decurso do século XX (Johnson, 1972). ${ }^{1}$

Deste modo, com a entrada em cena de novos atores institucionais instaura-se um enquadramento que faz multiplicar as interrogações quanto aos cenários do profissionalismo médico, uma vez que a legitimidade normativa das orientações managerialistas (Correia, 2012; Silva, 2012) que estão subjacentes às restruturações políticas e à implementação de novas regras e mecanismos de financiamento do setor público dos cuidados de saúde passa a estar desvinculada, em sentido estrito, do poder dos profissionais. No entanto, e longe de tal implicar um cenário de inexorável ocaso do poder profissional da medicina, aquilo a que se tem assistidoé à emergência de novas dinâmicas que são denotativas de uma tendência de adaptação resiliente da profissão médica, sobretudo por via de alianças estratégicas com outros grupos e atores no campo da saúde (Timmermans e Oh, 2010), bem como através de negociações políticas e compromissos institucionais no âmbito da esfera governativa (Correia, 2012).

Esta linha de análise coloca em evidência o facto de que associadas a estes processos regulatórios têm também emergido condições propícias ao desenvolvimento de novos equilíbrios e dinâmicas de reforço e legitimação do profissionalismo médico, no sentido em que alguns segmentos da profissão médica, mais do que incorporarem passivamente a abordagem managerialista, "colonizam-na" ativamente, resultando daí um reforço importante no seu poder profissional, nomeadamente a uma escala organizacional (Kuhlmann, 2006). Verifica-se, assim, que apesar dos processos de produção e formulação de NOC poderem envolver vários atores, alguns dos quais efetivamente externos ao campo médico (Timmermans e Epstein, 2010), uma parte muito importante do protagonismo destes processos é, na verdade, assumido pelos profissionais médicos, sobretudo quando estão em causa processos de definição, negociação e estabilização das NOC no quadro de painéis de peritos (Castel, 2009; Hodgetts, Elshaug e Hiller, 2012; Knaapen, 2013), ou a sua implementação nas escalas locais (McDonald e Harrison, 2004; Moreira, 2005).

1 No âmbito da literatura especializada no campo da sociologia das profissões, proliferam várias abordagens teóricas acerca do poder profissional, designadamente da medicina, que evidenciam a existência de uma tensão entre as linhas de análise que sustentam a existência de condições de manutenção de poder e monopólio profissionais e as que enfatizam a acentuação do declínio desse poder. Trata-se de uma controvérsia que mantém a sua relevância, embora seja necessária prudência analítica quando se interpreta o impacto das transformações que têm marcado os desenvolvimentos recentes do setor dos cuidados de saúde. Nesse sentido, e como se verá, qualquer sustentação teórica ancorada em pressupostos de elevada generalização quanto ao significado das reconfigurações profissionais da medicina - efetivamente mais sujeita a um controlo administrativo - tem de ser devidamente equacionada face à diversidade de situações empíricas que são denotativas de novas configurações do profissionalismo médico. 
Neste sentido, a ideia que importa ressalvar, enquanto eixo principal de análise, prende-se com a constatação de que, apesar do enquadramento regulatório instaurado pela governação clínica se traduzir numa ênfase normativa e institucional na lógica da prestação de contas e da validação externa da jurisdição profissional, a vulnerabilidade da profissão médica às interferências externas acaba por ser, todavia, "relativamente" contingente. Em particular quando uma das componentes importantes associadas à padronização do trabalho profissional, como é o caso da implementação de NOC, é maioritariamente desenvolvida a partir do interior da profissão, passando a configurar-se como uma oportunidade estratégica de participação dos profissionais nos processos de mudança (Timmermans e Berg, 2003).

\section{Sobre a afirmação profissional da MGF em contextos de mudança}

Considerando o processo formal de implementação das NOC em Portugal, iniciado formalmente a partir de finais de 2011, o objetivo específico subjacente à discussão analítica a empreender neste artigo é explorar as razões que explicam a adesão a esta lógica de padronização por parte da medicina geral e familiar (MGF), sobretudo se se tiver em linha de conta que se trata de uma especialidade médica cujos principais elementos distintivos da sua identidade profissional se ancoram numa orientação dita biográfica, holista e que confere acentuado privilégio, no âmbito das relações terapêuticas, aos julgamentos clínicos relativos aos casos individuais.

Assim, e se no imediato tal parece remeter para uma situação algo paradoxal, aquilo que, em contrapartida, uma abordagem centrada nas caraterísticas deste processo faz salientar é o de que este configura uma dinâmica que é sobretudo denotativa do reforço da profissionalização de um segmento ocupacional da profissão médica, os outrora chamados clínicos gerais. Este segmento foi historicamente objeto de uma secundarização gerada na dinâmica das especializações (principalmente no decurso do século XX), traduzindo-se esse estatuto em níveis mais restritos de poder, dominância e prestígio no interior da própria profissão (Armstrong, 1979; Calnan e Gabe, 2009; Pickard, 2009).

Com efeito, existe a montante da afirmação profissional da MGF uma trajetória histórica de mais de meio século marcada pela exclusão desta área do processo da especialização médica, dado que este foi crescendo e legitimando-se no âmbito da medicina hospitalar (Weisz, 2003). Este facto está diretamente conectado com a própria reconfiguração do perfil científico da medicina a partir de finais do século XIX, período a partir do qual se desenvolve um enfoque fortemente centrado na realidade orgânica do corpo e da patologia, em resultado de uma articulação cada vez mais estreita entre a prática médica e o conhecimento biológico básico. O desenvolvimento da investigação patológica passa, assim, a providenciar as condições indispensáveis à consolidação de uma conceção anatómica de doença (Porter, 2006; Timmermans, 2005). ${ }^{2}$ Como consequência, esse gradual predomínio de uma visão mais abstrata e objetificada de doença que foi instaurada pela medicina clínico-patológica acabou por concorrer de forma determinante para que a vertente hospitalar ganhasse um claro ascendente sobre a clínica geral, tornando-se, deste 
modo, a cosmologia médica dominante (Jewson, 1976) em detrimento da medicina "à cabeceira do doente".

A este propósito, Armstrong (1979) refere que os médicos hospitalares passaram a assumir um papel dominante, particularmente ao nível da produção do próprio conhecimento médico. Aliás, o domínio dos problemas indeterminados (como as patologias orgânicas mais complexas) concorreu de forma decisiva para o estabelecimento de uma lógica de hierarquização de tarefas em que o hospital (e, portanto, também os médicos hospitalares) assume $(\mathrm{m})$ o primado face à clínica geral numa relação de crescente assimetria e subordinação. Ou seja, os médicos de clínica geral tornaram-se meros consumidores do conhecimento médico produzido através da investigação clínica que o hospital proporcionava e circunscreveram-se a um papel de referenciação, quando os casos clínicos com que lidavam transcendiam as situações típicas da sua prática profissional, isto é, os casos dos doentes "triviais" com problemas comuns, menores e, como tal, não elegíveis para a abordagem mais específica em que se foi ramificando a medicina hospitalar.

Neste sentido, a crescente legitimação da especialização médica de cariz hospitalar - amplamente reforçada pelos desenvolvimentos laboratoriais durante o período entre guerras, especialmente no campo das inovações terapêuticas - foi tornando mais acentuada a exclusão dos clínicos gerais desse processo, o que conduziu à promoção e à dominância da ideologia hospitalar. Aliás, os primeiros indícios relativamente a uma tentativa de inflexão desta clivagem intraprofissional só se começaram a verificar no início da década de 1950, altura em que, particularmente no Reino Unido, é criado o Colégio de Clínica Geral (1952) que desempenhou, no decurso dos anos seguintes, um papel de relevo no início da emancipação da clínica geral face à medicina hospitalar (Armstrong, 1979; Checkland et al, 2008; Ramos, 1987).

Mas é fundamentalmente a partir da década de 1960 que se começa a assistir a um efetivo ressurgimento da clínica geral, sobretudo por via das tentativas de redefinição do seu papel profissional e da natureza da sua prática. Esta é (re)configurada como uma medicina biográfica, concretamente quando o seu modelo de prática acentua a importância do indivíduo inserido no seu contexto social. Esta abordagem de feição biopsicossocial permitiu, assim, a conquista de um modelo próprio e, por consequência, a crítica e a demarcação face ao modelo biomédico da medicina hospitalar e à consequente atomização que a lógica da especialização médica induz. A doença deixa de ser entendida numa perspetiva mecanicista e estritamente orgânica, e passam a valorizar-se outras dimensões mais globais e tidas

2 No quadro de uma crescente intervenção do estado e das universidades em matéria de investigação científica em medicina, particularmente em França (Porter, 2006), o hospital - enquanto espaço privilegiado para a investigação e para o treino científico no estudo da doença - mas também o laboratório - enquanto local privilegiado para a experimentação -, desempenharam um papel decisivo na transição de uma "medicina de cabeceira", centrada no doente, para uma "medicina hospitalar". O perfil científico desta última passará a estar mais notoriamente centrado na doença (Lupton, 1994), assinalando, deste modo, a crescente importância dos sinais físicos (as lesões orgânicas, tidas como objetivas e constantes) em detrimento dos sintomas, vistos como demasiado variáveis e subjetivos. 
como constitutivas da especialidade da "pessoa doente" (Checkland et al. 2008), concretamente as que remetem para uma lógica de cuidados centrada na proximidade, globalidade e pessoalidade (Jordão, 1995; Sá, 2002).

No caso português acresce a esta tendência o facto de que as condições para o estabelecimento da institucionalização da MGF só se vão tornando mais notórias no decurso das décadas de 1980 e 1990, pois é somente durante esse período que se concretizam aspetos cruciais como a criação dos institutos de clínica geral (1981), a regulamentação da carreira médica no SNS e respetiva definição do perfil profissional do médico de clínica geral (1982), a criação do Internato Complementar de Clínica Geral (1982), ou a constituição do Colégio de Clínica Geral na Ordem dos Médicos (1982). Estabelecem-se, também, as primeiras iniciativas ${ }^{3}$ que tinham como horizonte a implementação de enquadramentos organizacionais mais consentâneos com o projeto profissional da MGF, designadamente em termos de desvinculação quanto às restrições decorrentes de um controlo administrativo do estado que, pelo menos até à Reforma dos Cuidados de Saúde Primários (CSP) de 2005 (Teixeira, 2012), coarctou as possibilidades de afirmação de uma carreira que sempre se debateu para se afastar das franjas e dos lugares mais periféricos da profissão médica.

Estas vicissitudes são, portanto, indicativas de uma carreira sociossimbólica que remete para uma profissão que lida, desde a sua génese, com constrangimentos ao nível do seu prestígio social, da sua autonomia, e do seu lugar no quadro da produção e reprodução do poder do conhecimento médico (Carapinheiro, 2006; Teixeira, 2012). Tal ajuda a compreender a cristalização de posições estruturais diversas na divisão do trabalho médico, designadamente porque estas se traduzem em poderes desiguais e autoridades diferenciadas no sistema de saúde. E traduzem-se também na desqualificação dos saberes e competências de uma especialidade médica cuja "juventude" não a dota de igual modo dos "atributos de prestígio e poder acumulados pelos médicos hospitalares e sobre a base de uma cultura hospitalocêntrica, que sempre atravessou e ainda atravessa o sistema de saúde português"' (Carapinheiro, 2006: 151-152).

\section{Metodologia}

A estratégia de investigação que foi desenvolvida nesta pesquisa ${ }^{4}$ insere-se no quadro de uma metodologia qualitativa-intensiva, tendo a mesma sido alicerçada na

3 As tentativas de implementação de inovações organizacionais potencialmente promotoras da concretização do projeto de ampliação e reforço de prerrogativas profissionais tornaram-se mais notórias a partir da década de 1990. Iniciativas como o "Projeto Alfa" (1996-98), o "Regime Remuneratório Experimental" (1998-2005) ou o "Tubo de Ensaio" (1998-2004) foram, assim, etapas preambulares de um processo que instaurou novas lógicas de trabalho, de avaliação e de remuneração (cf. Miguel, 2010; Teixeira, 2012).

4 Esta pesquisa foi desenvolvida no âmbito de uma tese de doutoramento em Sociologia (Raposo, 2014). Neste artigo apresenta-se apenas uma parte circunscrita dos resultados empíricos decorrentes dessa investigação, especificamente os que se enquadram no âmbito da discussão analítica que aqui é proposta. 
pesquisa de terreno enquanto método principal, designadamente através do recurso à observação direta (por via da participação em reuniões médicas semanais), bem como por via da realização de sessões de grupos focais no âmbito dos contextos organizacionais típicos destes especialistas (Raposo, 2014: 43-54).

Contudo, e considerando o objetivo específico de perceber as respostas e as adaptações da MGF face às transformações de um quadro político e institucional crescentemente alicerçado em novas lógicas regulatórias, que conferem uma centralidade instrumental aos critérios de evidência científica e à sua tradução em mecanismo de padronização, torna-se fundamental mobilizar elementos empíricos alusivos ao processo de implementação das NOC. Trata-se de uma opção que, nesta perspetiva, confere privilégio à técnica qualitativa das entrevistas semiestruturadas junto de um número restrito de informantes privilegiados, ${ }^{5}$ mesmo que no quadro geral da pesquisa de terreno esta tenha desempenhado um papel complementar face às técnicas principais já referidas. Para o propósito de mapear as dinâmicas e as circunstâncias do processo no contexto profissional da MGF, o contributo que estas entrevistas proporcionaram foi de uma utilidade efetiva.

Neste âmbito concreto são, então, mobilizadas as entrevistas realizadas junto do então presidente da Associação Portuguesa de Medicina Geral e Familiar (APMGF), do director do Centro de Estudos de Medicina Baseada na Evidência (CEMBE) e de um membro da Comissão Científica para as Boas Práticas Clínicas (CCBPC). Em todos os casos, a razão principal que presidiu a esta escolha prendeu-se com o interesse em enquadrar o impacto das novas orientações regulatórias no desenvolvimento profissional da MGF.

Importa ainda referir que, como suporte documental a este aprofundamento, se recorreu a documentação institucional e a alguma legislação, sobretudo em função das necessidades de melhor caraterização e definição da natureza normativa de algumas decisões e orientações políticas no campo da saúde, designadamente ao nível dos cuidados de saúde primários (MS, 2004; MCSP, 2006).

\section{Apropriações e reconfigurações estratégicas: uma MGF baseada na evidência?}

Situando a análise no caso específico da implementação das NOC em Portugal, e da sua respetiva expressão e impacto no âmbito da MGF, é possível verificar que, em bom rigor, não se tratou de um processo totalmente inusitado e alheio às próprias dinâmicas de desenvolvimento profissional desta especialidade, na medida em que se verificou um certo alinhamento e envolvimento ativo da MGF relativamente aos requisitos da padronização, da objetividade e da transparência da prática clínica.

$5 \quad$ No total foram levadas a cabo dez entrevistas com estas caraterísticas, tendo as dimensões chave dos guiões sido adaptadas às especificidades dos papéis institucionais dos diferentes atores. Todavia, o caráter mais delimitado da discussão levada a cabo neste artigo, "apenas" solicita a mobilização de três dessas entrevistas, dada a sua centralidade para clarificar a lógica de envolvimento da MGF no processo de implementação das NOC. 
Procurando ancorar este argumento geral na realidade empírica que aqui é tomada como referência, um primeiro aspeto significativo a destacar é o de que o horizonte da vinculação do trabalho profissional à evidência científica das NOC não é uma realidade completamente nova na MGF, na medida em que, no âmbito do desenvolvimento socioprofissional desta especialidade, houve iniciativas claramente convergentes com este tipo de lógica normativa associada a orientações mais padronizadas. A familiaridade com as normas emitidas pela Direcção-Geral de Saúde (DGS), numa fase ainda anterior à implementação formal das NOC, é assumida pelo então presidente da APMGF ${ }^{6}$ como uma caraterística que coloca em evidência a precocidade da MGF no seu envolvimento com um processo que, de algum modo, constitui uma antecâmera dos desenvolvimentos mais recentes associados ao processo implementação das NOC. Assim, e tal como é referido por este dirigente,

\begin{abstract}
Mas também a DGS, antes de existirem estas normas mais recentes, eram emitidas circulares normativas que os médicos de família (MF), nos centros de saúde, sempre foram, vá lá, emblemáticos, na sua utilização. Se fosse aos hospitais, aos cuidados hospitalares, raro era o colega que tinha conhecimento dessas circulares normativas, para a doença coronária, para a hipertensão arterial, para a diabetes mellitus que são as áreas mais importantes, para a asma, por exemplo, não tinham conhecimento. Os MF, inclusive, para fazer o seu exame de saída de especialidade, eram questionados sobre as normas da DGS. [...] Por isso é que eu sempre disse que esta grande implementação de normas que agora vem da DGS não nos assusta e estamos obviamente abertos e seremos certamente dos que estaremos na linha da frente em termos da sua utilização, implementação e aplicação no terreno [presidente da APMGF].
\end{abstract}

Com efeito, a trajetória de afirmação profissional da MGF cedo a levou a desencadear não só estratégias de aproximação às iniciativas políticas mais orientadas para a concretização de alterações no setor dos CSP, como foi suscitando preocupações de progressivo reforço do perfil científico da especialidade, tendo em vista a sua institucionalização. Este discurso de aparente voluntarismo da MGF em aderir precocemente às orientações normativas da DGS, independentemente de algum empolamento retórico, é, acima de tudo, indicativo de que o percurso de afirmação profissional da MGF nunca se fez de uma forma divorciada do enquadramento político e institucional, pelo que a sua articulação às lógicas de regulação externa se constitui como um traço importante da sua trajetória, designadamente a partir da década de 1990. Convergente com esta linha de interpretação analítica, o excerto seguinte torna ainda mais explícita esta ideia:

[...] para nós não é surpresa e não temos qualquer problema em lidarmos com este cenário porque desde há cerca de 20 anos, que mesmo não havendo oficialmente NOC,

6 À altura da realização da entrevista (dezembro de 2011), o então presidente da APMGF era o anterior ao que exerce atualmente o mandato. 
nós sempre tentámos implementar na nossa prática clínica normas que importámos do Reino Unido, de Espanha e como temos uma boa parceria com estes países, e nomeadamente, com a Espanha, com a sociedade espanhola de medicina familiar e comunitária, e também com os colegas da Holanda que eles próprios, enquanto sociedades científicas foram construindo NOC, nós importámo-las e tentámos sempre na nossa prática diária incorporar esses instrumentos de trabalho para basear as nossas decisões na melhor evidência científica [presidente da APMGF].

Relativamente ao investimento explícito da MGF em dotar-se de instrumentos formais, como as NOC, pode-se considerar que também nesse aspeto a precocidade dessa aproximação é sugestiva de uma aposta estratégica orientada para a consolidação do seu perfil científico e profissional e, portanto, de um reforço da sua jurisdição profissional (Abbot, 1988). Substantivando esta afirmação, é possível fazer notar que a MGF, através da sua associação profissional (APMGF) tem vindo a estabelecer uma colaboração regular com o CEMBE, não só ao nível de várias iniciativas de formação pós-graduada avançada, mas também ao nível de uma colaboração de caráter mais institucional, destacando-se neste último caso o estabelecimento de uma parceria estratégica celebrada em 2009 com o propósito de a APMGF dispor, ela própria, de um conjunto de NOC.

Ao abrigo desse protocolo, esta iniciativa em particular traduziu-se num projeto de colaboração em que o CEMBE assegurou a tradução e adaptação para português de um conjunto de dez NOC finlandesas, com o propósito de que estas se constituíssem como um apoio à atualização dos conhecimentos de todos os MF e à qualificação do seu exercício profissional. O enquadramento deste processo e a ênfase colocada no tipo de papel desempenhado pelas NOC sublinhou a ideia de que estas devem ser entendidas como instrumentos de formação médica e de desenvolvimento profissional contínuo, o que significa que houve uma tentativa de modular o processo de formalização e codificação do conhecimento numa lógica de autorregulação (centrada na dimensão formativa) substancialmente distinta da habitual ênfase regulatória que subjaz às preocupações de eficiência das intervenções médicas.

Foi uma tentativa da própria associação trazer e adaptar para Portugal NOC estrangeiras. Aliás, a tentativa mais recente até foi em parceria com o CEMBE do professor Vaz Carneiro em que, por protocolo com uma associação finlandesa, importámos e adaptámos para português NOC de colegas finlandeses em que há as técnicas mais avançadas de MBE. [...] Eu diria que deve ser já a terceira tentativa que nós fazemos em Portugal, a associação, de tentar adaptar para a prática clínica portuguesa guidelines que vêm de fora. Diria que Reino Unido, Holanda, Espanha e Finlândia foram os países em que nós baseámos mais essa prática [presidente da APMGF].

À luz destas considerações torna-se bem patente a ideia de que a aproximação a estes instrumentos se tem tornado num dos vetores principais que melhor reflete a crescente incorporação das metodologias científicas de apoio à decisão médica, tal como preconizadas pela $\mathrm{MBE}$, bem como a própria valorização do conhecimento proveniente 
da investigação clínica. A constatação relativa à existência de uma afinidade institucional com a abordagem epistemológica da MBE, bem como com os instrumentos de sistematização da evidência científica, permite destacar a ideia de que a incorporação deste tipo de evidência na formação científica da MGF tem ganho um maior protagonismo, tornando-se, inclusivamente, um ponto incontornável nos eventos científicos desta especialidade, tal como se pode verificar pela leitura do seguinte excerto:

Temos, por exemplo, todos os anos, em março, o nosso encontro nacional de MGF que é sempre em Vila Moura. E nesse encontro o professor Vaz Carneiro vai sempre apresentar oito evidências, que se revelaram como fundamentais para a prática clínica do MF. É um momento sempre chave do encontro, o momento alto do encontro. [...] São em áreas sempre fundamentais, invariavelmente na parte cardiovascular, diabetes mellitus, obesidade, estilos de vida, hipertensão arterial, doença pulmonar obstrutiva crónica, asma... são as áreas importantes da nossa consulta. Que tomam o maior volume de causa na nossa consulta. [...] Para além, obviamente, das ações de formação que o professor Vaz Carneiro foi sempre fazendo a MF e que tiveram a chancela científica da APMGF [presidente da APMGF].

De facto, e no que diz respeito a esta iniciativa das "oito evidências clínicas" relativas a um determinado ano e que se revelaram pertinentes para os CSP, passou a constituir-se como algo de fundamental e que se tem vindo a repetir desde 2009, altura em que, por ocasião do 26. ㅌ. Encontro Nacional da Clínica Geral, esta iniciativa foi apresentada. Estas evidências são selecionadas e comentadas pelo diretor do CEMBE que, para além de as apresentar no encontro nacional, também as sistematiza numa publicação interna da APMGF. Como o próprio refere no prefácio das oito evidências relativas ao ano de 2010,

O projeto das "Oito Evidências" vem tentar apoiar parcialmente a atualização de conhecimentos. O objetivo principal deste trabalho tem sido alertar o médico de família (MF) para avanços nas áreas da sua prática clínica - Medicina, Cirurgia, Obstetrícia/Ginecologia, Pediatria e Saúde Mental - selecionando artigos com os seguintes critérios: publicação integral em revistas médicas, relevância clínica para a MGF, aplicabilidade prática no quotidiano, oportunidade clínica (novos medicamentos, por exemplo), avaliação crítica detalhada com resultados positivos e a prevalência das doenças de base (Carneiro, 2011: 3).

Ainda tomando como referência as palavras do diretor do CEMBE, é possível confirmar não só a natureza da parceria institucional entre este centro e a APMGF, mas também o reconhecimento de que a MGF se tem afirmado como uma das especialidades médicas que de forma mais efetiva se tem aproximado das abordagens da $\mathrm{BEM}^{7}$ e que, por consequência, se tem redefinido de forma consequente ao nível dos pressupostos científicos da sua formação:

[...] ofereci uma série de cursos a eles, portanto as pessoas mais interessadas, e porque eles têm, por exemplo, na revista deles têm uma secção só disto; hoje em dia, 
normalizaram-se procedimentos e arranjaram-se sistemas de informações, têm feito um enorme esfoço para usarem sistemas de informação de alta qualidade. Portanto se há uma área em que eu ache que as coisas estão a correr relativamente bem é a área da MGF. Claro está que há pessoas que estão completamente perdidas no meio dos bosques, mas de uma maneira geral, como especialidade, eles têm feito um enorme esforço, uma formação avançada, até porque para eles é muito importante este prestígio de se ter uma base de evidência sólida, não é? Quer dizer, para eles é essencial serem respeitados nessa base, portanto eu penso que eles estão mais adiantados que a maior parte das outras especialidades, na minha opinião, e isto por causa do que disse. Muitos cursos que eu faço com eles, e muitas explicações que eles fazem. Têm uma visão notável e muito precisa e muito bem pensada sobre o que é tudo isto da evidência para a MGF [director do CEMBE].

Como se torna notório nestas considerações, o facto de existir uma crescente familiarização com as metodologias desta abordagem e um reforço das competências técnicas que permitem aferir a qualidade científica dos instrumentos codificados mostra a existência de um efetivo investimento ideológico numa dimensão científica que estaria, à partida, nos antípodas dos fundamentos da MGF, uma vez que os pressupostos da MBE remetem para uma base mais biomédica. Deste modo, embora a enfatização do discurso humanista e da orientação holista - que são os pilares que conferem especificidade ideológica a esta especialidade - , permaneçam como o principal marcador das conceções identitárias, estas passam agora a mobilizar outros fundamentos que acentuam o reforço do seu estatuto e autoridade profissional, dado que a MBE conota a medicina a um perfil de maior cientificidade.

Trata-se, com efeito, de um aspeto particularmente importante, dado que a questão da apropriação estratégica da abordagem da MBE para efeitos de consolidação da afirmação profissional da MGF é reveladora de dinâmicas de reforço da jurisdição médica. Constitui-se, portanto, como uma oportunidade para sedimentar a legitimidade da autoridade profissional (Geltzer, 2009; Pickard, 2009) e uma

7 Seria, sem dúvida, expectável que a especialidade de MGF conferisse um maior privilégio à autonomia clínica num sentido mais próximo do ethos humanitário da medicina e não tanto na incorporação sistemática de normas de orientação clínica decorrentes de metodologias científicas resultantes de evidência baseada em critérios de prova estatística. Contudo, e considerando o inventário das atividades de formação e divulgação levadas a cabo pelo CEMBE, nomeadamente em termos de realização de vários cursos de pós-graduação e de educação médica contínua em vários hospitais e universidades portuguesas (Raposo, 2014), verifica-se que uma parte importante da procura de cursos pós-graduados de atualização sobre MBE é protagonizada pela MGF. Esta importância estratégica conferida à MBE acaba, assim, por produzir reconfigurações epistemológicas, mas também reconfigurações identitárias importantes. A vinculação aos conhecimentos específicos que a MBE solicita passa a constituir-se como um elemento diferenciador e distintivo face, nomeadamente, às outras especialidades hospitalares, algo que foi muito notório nas sessões de grupos focais com os profissionais (Raposo, 2014), no sentido de as posições destes (sobretudo dos internos) serem moldadas por estratégias discursivas de distinção e pela produção simbólica de processos de desqualificação das outas especialidades (Carapinheiro, 1991), alegadamente menos permeáveis a moldar a sua prática clínica em coerência com a evidência científica das NOC. 
possibilidade de reforçar o estatuto profissional por via de uma maior consistência científica, que justifica o seu monopólio de competências e as prerrogativas decorrentes da negociação associada ao estabelecimento da sua jurisdição profissional (Timmermans e Berg, 2003).

Nesta medida, e atendendo às palavras do presidente da APMGF, esta linha de interpretação parece ganhar consistência, sobretudo quando se olha panoramicamente para as orientações diferenciadas que têm vindo a moldar a trajetória profissional desta especialidade:

Não vemos a MBE como a única resposta e como a única solução para o apoio à decisão clínica mas certamente que nesta vertente tentámos agora tornar mais forte e mais presente na associação, no fundo tentar dar uma imagem mais de sociedade científica à associação porque no fundo somos também a sociedade científica da MGF. Tentámos obviamente que a MBE fosse um dos setores a apostar com maior premência. Também foi, a par da investigação, porque são dois contextos importantíssimos, estão muito relacionados obviamente, foram as duas componentes que tentámos dar maior força neste mandato da presente direção. Isto foi um processo que veio da anterior direção em que em 2007/2008 se tentou reorientar a estratégia a nível da associação no sentido de dar um maior peso à parte técnico-científica. Porque a associação, desde a sua fundação, em 1983, sempre esteve muito conotada à ação política e à ação socioprofissional e não querendo deixar essas duas dimensões, que são fundamentais, quisemos uma reorientação estratégica; dar maior peso à componente técnico-científica. E certamente que a MBE se inscreve nessa aposta [presidente da APMGF].

\section{O envolvimento e a negociação dos profissionais no processo de implementação das NOC em Portugal}

Relativamente às caraterísticas deste processo no âmbito da realidade portuguesa é importante clarificar que apesar do caráter preambular de algumas iniciativas mais precoces - como as que foram concretamente encetadas pela APMGF, as resultantes de documentos de reflexão estratégica, nomeadamente pela ARSLVT, ${ }^{8}$ ou a definição, por parte da DGS, da Estratégia Nacional para a Qualidade na Saúde ${ }^{9}-$ a emergência da implementação efetiva das NOC a uma escala nacional e generalizada a todo o campo profissional da medicina só ocorre a partir de meados de 2011, já

8 Um documento da Administração Regional de Saúde de Lisboa e Vale do Tejo (ARSLVT), datado de 2009, e intitulado "Nos 30 anos do SNS/Governação dos Hospitais/Conclusões de um grupo de trabalho da ARSLVT 2009", considerava que o SNS deveria investir na elaboração e implementação de NOC.

9 Ao nível da" qualidade clínica" esta estratégia estabelece como objetivos fundamentais os seguintes aspetos: "Reduzir a variabilidade da prática clínica; tornar obrigatória a normalização clínica respeitando a decisão clínica individual fundamentada; aumentar a clínica reflexiva; criar redes de governação clínica; disseminar auditorias clínicas; estimar impactes de saúde e financeiros; avaliar resultados; responsabilizar as Direções Clínicas", cf. Despacho n.․ 14223/2009, DR n.․ 120 de 24/06/2009. 
no quadro das imposições inscritas no memorando de entendimento com a Troika, ${ }^{10}$ concretamente ao nível dos imperativos de maior eficiência no setor da saúde. Por essa razão, pode-se considerar que, sendo verdade que este tipo de instrumentos tem sido tradicionalmente da responsabilidade da DGS, não menos incontornável é a constatação relativa ao caráter algo errático, heterogéneo e inconsistente destes processos no período anterior a este novo contexto político (Vaz, 2012).

De facto, um dos aspetos principais que resulta destas considerações prende-se com o reconhecimento de que é no contexto de uma conjuntura adversa que as NOC se afirmam como um instrumento fundamental. Não apenas ao nível dos seus alegados contributos para a melhoria da qualidade da prestação dos cuidados de saúde, mas também em termos da otimização da alocação dos recursos e da redução da despesa em saúde, nomeadamente ao nível da prescrição dos medicamentos em ambulatório e dos meios complementares de diagnóstico e terapêutica com maiores encargos financeiros para o Serviço Nacional de Saúde.

Elucidativo deste ponto em particular é, sem dúvida, o teor do já referido memorando de entendimento, especialmente alguns dos objetivos enquadrados nas medidas orçamentais estruturais, e em concreto as que se reportam ao domínio da saúde, como é o caso da medida 3.59 (orientações de prescrição para os médicos à luz das orientações internacionais de prescrição) e 3.73 (prosseguimento das NOC e criação de um sistema de auditoria da sua implementação).

Neste sentido, para a concretização desta política a DGS promoveu um protocolo com a Ordem dos Médicos (OM), celebrado a 05/09/2011, que estabelecia que as NOC estariam sujeitas ao prévio acordo da OM e que as auditorias seriam também realizadas com a cooperação direta destas duas instituições. A elaboração destes instrumentos previa um processo de avaliação do seu conteúdo, composto por diversas etapas de apreciação técnica com vista à sua validação e aprovação final. O projeto de cada NOC seria elaborado por peritos oriundos dos colégios de especialidade da OM e das sociedades científicas, a que se seguiria um período de discussão pública e de avaliação interpares. Os contributos daí provenientes seriam avaliados pela DGS, seguindo-se a revisão científica do conteúdo final de cada projeto de NOC pelo consultor científico do Departamento da Qualidade na Saúde da DGS. Só após essa etapa é que cada projeto de NOC seria submetido a um último crivo de validação científica, desta feita por parte da CCBPC, ${ }^{11}$ momento a partir do qual se consideraria que uma determinada NOC estaria finalizada e pronta a ser auditada.

$\mathrm{Na}$ fase inicial deste processo foi estabelecido como objetivo a perspetiva de implementação de 90 NOC (60 em 2011 e 30 em 2012), mas rapidamente essa meta deixou de ser concebida como viável, ${ }^{12}$ devido, justamente, ao elevado volume de

10 Trata-se de um imperativo que decorre das orientações fundamentais inscritas no Memorando de Entendimento sobre as Condicionalidades de Política Económica, assinado pelo estado português com a (vulgarmente designada) Troika, a 17 de maio de 2011, designadamente ao nível das medidas de reforma estratégica para o setor da saúde.

11 A CCBPC foi inicialmente constituída através do Despacho n. ${ }^{\circ}$ 12422/2011, de 20/09/2011, tendo a sua composição sido posteriormente reformulada e ampliada através do Despacho n⿳o 7584/2012, de 01/06/2012. Passou, assim, a contar com 28 elementos em situação de paridade entre os membros propostos pela DGS e pela OM. 
NOC, e também devido a algumas falhas na estratégia institucional de implementação. Essas falhas foram não só de natureza técnica e logística (um número excessivo de NOC a implementar simultaneamente), mas também normativa, dado que nessa fase inicial prevaleceu uma imagem de obrigatoriedade com implicações penalizadoras face ao seu incumprimento.

Foram, aliás, esses aspetos os principais responsáveis pela emergência de conceções e expetativas ambivalentes junto dos médicos, e em particular dos especialistas de MGF, pois se em matéria de princípios gerais o processo em si foi globalmente aceite como razoável e potencialmente vantajoso para a melhoria da qualidade da prática clínica (as NOC como instrumentos úteis de apoio à decisão clínica), não deixou, no entanto, de gerar ceticismo, reservas e receios relativamente não só à perspetiva de implicações legais e profissionais associadas à obrigatoriedade do seu cumprimento, mas também quanto à própria qualidade científica desses instrumentos. Ilustrativas deste último ponto são, por exemplo, as considerações de um dos membros da CCBPC, especialista em MGF, quando desenvolve o seguinte argumento baseado na experiência concreta do trabalho desenvolvido por esta comissão:

Eu tenho uma perspetiva um bocadinho negativa da forma como tem acontecido. [...] Nasceu de uma pressão muito grande, até externa, de uma pressão muito mais baseada em aspetos económicos do que qualquer outro tipo de..., e portanto o que temos é claramente isto: num período relativamente curto de tempo foram colocadas para discussão, quase uma centena de normas. [...] Consistiu essencialmente em identificar normas que já existiam, publicadas em outros países, sobretudo em língua inglesa, traduzir essas normas e tentar de alguma forma adaptá-las à realidade portuguesa sem que houvesse um conjunto de orientações claras, sem que houvesse nas próprias equipas que fizeram este processo algum fio condutor ou mesmo algum objetivo definido a não ser ter o máximo de normas possível num curto espaço de tempo. Bom, isto levou a que algumas dessas normas são... Primeiro, não há garantia que sejam baseadas em evidência científica, muitas delas não têm recomendações, não traduzem a sua recomendação nos elementos que habitualmente são usados [...] ficamos com a ideia que são apenas recomendações de peritos, não é? [...] e algumas delas não estão claramente adaptadas, ou estão mal adaptadas à realidade portuguesa, e outras têm erros grosseiros [membro da CCBPC].

Com efeito, essa discussão quanto às limitações, ora processuais ora mais substantivas, do processo coloca em evidência um conjunto de dúvidas e argumentos críti$\cos$, não só sobre a validade científica subjacente à elaboração das referidas NOC, mas também as questões de aplicabilidade no contexto da prática clínica, designadamente nos modos de compatibilização com outros critérios de decisão ou fontes de informação. Neste sentido, portanto, os aspetos que desde o início têm suscitado

12 No início de 2013, somente seis NOC estavam formalmente validadas à luz da metodologia definida para a sua aprovação. 
os posicionamentos mais críticos são os que se relacionam com a discussão em torno do próprio estatuto das NOC, dado que o ponto de clivagem fundamental se centra na ideia de que estas devem ser consideradas como orientações gerais, não impositivas, e, como tal, necessariamente adaptadas aos contextos locais e aos doentes individuais.

Esta preocupação em estabelecer este tipo de demarcação tem também sido notada noutros contextos (Greenhalgh, 2006: 134), no sentido em que a preservação do espaço para a interpretação e para o julgamento individual é, no fundo, o requisito que torna possível a manutenção da discricionariedade. É, portanto, por essa razão, que uma das preocupações fundamentais consistiu na tentativa de garantir a participação dos médicos de família na elaboração e discussão das normas (Battista, Hodge e Vineis, 1995), dado que uma das ideias que mais ecoou nos diversos fóruns de discussão era a de que este processo era uma inevitabilidade que se iria concretizar com ou sem os médicos, pelo que importava assumir a iniciativa de serem os próprios profissionais a assegurar a elaboração e validação das normas, de modo a não ficarem sujeitos a imposições exógenas à própria profissão. Esta preocupação em tentar controlar, ou modelar, o processo evidencia, assim, a razão pela qual os profissionais procuraram matizar o caráter prescritivo das NOC em benefício da ênfase nas suas virtudes formativas e de suporte técnico às decisões clínicas, tendo sempre como principal sustentáculo argumentativo a necessidade de estas poderem ser adaptadas às contingências dos cuidados individualizados (Timmermans e Berg, 2003).

De facto, e em coerência com a análise de vários autores (McDonald e Harrison, 2004; Moreira, 2005; Knaapen, 2013), para o estabelecimento das NOC acaba por ser decisivo o envolvimento dos profissionais, em particular na concretização de consensos e de compromissos no desenvolvimento destes instrumentos. O processo de avaliação crítica da evidência e, sobretudo, o modo como esta acaba por ser muitas vezes articulada com outros critérios periciais (incluindo a experiência clínica), designadamente quando é considerado que não há robustez científica suficiente (Knaapen, 2013), mostra que o desenvolvimento das NOC depende efetivamente de vários consensos e compromissos.

No caso específico aqui em análise, essa lógica de compromisso entre as instituições promotoras, as sociedades científicas e os médicos, nomeadamente durante o período em que cada NOC se encontrava em processo de audição pública, mostra que há, de facto, uma processualidade própria que garante que a validação e a implementação destes instrumentos se tornem efetivamente viáveis.

Ora de acordo com este posicionamento estratégico, que reflete a negociação de um importante espaço de autonomia dos profissionais, ficou assegurado que as NOC não deveriam determinar a prática clínica, mas somente orientá-la, razão pela qual a ênfase inicial de teor mais impositivo das próprias auditorias foi dando lugar a uma perspetiva diferente que as vinculou mais à ideia de que estas se constituam como instrumento de melhoria da qualidade e de boas práticas, e não como instrumento punitivo e de culpabilização. Nessa medida foi preconizado que as auditorias seriam desenvolvidas e aplicadas numa lógica interpares, com caráter fundamentalmente pedagógico e contextualizando sempre os resultados de acordo com as caraterísticas das realidades locais. 
Aliás, um dos argumentos reiteradamente mobilizado para suportar esta salvaguarda enfatizava a ideia de que as situações de práticas de prescrição contrárias às normas se devem principalmente a constrangimentos na organização dos serviços, pelo que são estes que devem ser auditados. Verifica-se, assim, que a responsabilidade por algum eventual incumprimento é diluída nas particularidades dos contextos organizacionais, mas mesmo quando esse incumprimento remete para uma prática clínica mais individual é sublinhada a necessidade de se levar em linha de conta a consistência de muitas das razões e das particularidades da avaliação clínica que possam estar subjacentes a esse "desvio" relativamente a um cumprimento mais escrupuloso das NOC (Timmermans e Berg, 2003: 96).

Em relação a este último aspeto em particular, é salientada a garantia de que a margem de não cumprimento integral de uma determinada NOC esteja salvaguardada de qualquer avaliação regulatória que a enquadre como má prática clínica. Nesse sentido, as NOC não são entendidas como verdades científicas estabilizadas, mas sim como um instrumento da adaptação do trabalho clínico às dinâmicas e complexidades do contexto da sua prática (Battista, Hodge e Vineis, 1995: 879). O aspeto que é, portanto, bastante sublinhado - e que, aliás, vai ao encontro do direito consagrado no código deontológico da profissão relativo à excepcionalidade do cumprimento de orientações desta natureza ${ }^{13}$ - é o de que as razões que presidiram a essas decisões contrárias ao estipulado nas NOC estejam devidamente fundamentadas.

\section{Conclusão}

Uma das vertentes que reflete claramente a lógica de envolvimento ativo da MGF em processos diretamente conectados com o reforço da regulação, assim como da codificação do conhecimento para efeitos de prossecução de objetivos de "melhoria" da qualidade do desempenho profissional e organizacional, diz respeito ao processo de implementação formal das NOC. Com efeito, se é verdade que os processos de reforço da padronização, por via da disseminação destes instrumentos, tendem a suscitar uma receção ambivalente junto da profissão médica - a ameaça da interferência no espaço de julgamento profissional, por um lado, e uma possibilidade de reforço do estatuto profissional por via de uma maior consistência científica associada ao conhecimento especializado, por outro - , não deixa de ser notório que no caso desta especialidade esse envolvimento cedo se foi tornando uma realidade efetiva. Designadamente através de uma colaboração institucional bem concertada entre a APMGF e o CEMBE, ou através do envolvimento ativo

13 Segundo o artigo 13.ํㅡㅁo Código Deontológico da $\mathrm{OM}$ (referente à objeção técnica), é estipulado que "a recusa de subordinação a ordens técnicas oriundas de hierarquias institucionais, legal ou contratualmente estabelecidas, ou a normas de orientação adotadas institucionalmente, só pode ser usada quando o médico se sentir constrangido a praticar ou deixar de praticar atos médicos, contra a sua opinião técnica, devendo, nesse caso, justificar-se de forma clara e por escrito". 
desta associação (enquanto sociedade científica) e dos seus profissionais logo nas fases iniciais do processo de implementação das NOC.

Quanto à aproximação da MGF a estes instrumentos constata-se que a crescente incorporação das metodologias científicas de apoio à decisão médica na sua realidade profissional não tem, todavia, implicado o abandono ou o desvirtuamento radical da matriz do profissionalismo ocupacional desta especialidade e da sua identidade distintiva. Desde logo porque um aspeto que foi possível salientar a propósito do tipo de vinculação da MGF a este processo refere-se, justamente, ao modo como a concretização da implementação das NOC foi implicando uma lógica de negociação que assegurou - não obstante o "gatilho" desta dinâmica ter sido o resultado dos compromissos de medidas de reforma estrutural que o estado português foi forçado a assumir no quadro da assistência externa - a participação dos profissionais na própria modulação desta iniciativa.

É precisamente nesta medida que deve ser entendido o empenho dos médicos, e da MGF em particular, dado que esta reflete a tentativa de conquistar as garantias de que as NOC sejam concebidas e implementadas como instrumentos de formação médica e de desenvolvimento profissional contínuo. O obviar da carga impositiva destes instrumentos e a salvaguarda de que a definição e validação do seu conteúdo estão abertas à negociação e à redefinição constitui-se como um requisito fundamental, dado que, neste entendimento, o seu uso não conduz necessariamente à supressão da discricionariedade médica. A garantia de que, a par do compromisso de melhoria da prática clínica por via da utilização dos instrumentos de apoio à decisão, fica igualmente assegurado um espaço para a interpretação clínica, constitui-se, assim, como o elemento indispensável para permitir a proteção do julgamento profissional.

A ênfase que foi sendo reiteradamente desenvolvida estruturou-se a partir do argumento de que a complexidade e a heterogeneidade intrínsecas ao trabalho clínico se constituem como dimensões inalienáveis que extravasam o âmbito mais codificado das recomendações preconizadas pelas NOC, razão pela qual é justificada a precedência da autonomia clínica sobre os aspetos mais prescritivos das NOC. Aliás, a própria perspetiva de um eventual incumprimento das NOC face às particularidades de um determinado caso clínico é vista como algo de relativamente inevitável, e que ao acontecer "apenas" requer a devida fundamentação clínica para suportar as decisões que se revelam distintas das soluções ótimas que são indicadas nestes instrumentos.

Não é também por isso surpreendente que a evolução do processo de implementação das NOC se tenha centrado, a par do envolvimento na avaliação crítica do conteúdo científico destes instrumentos, na questão das auditorias. A dissipação da imagem "negativa" da obrigatoriedade e da penalização inerente às auditorias foi, de facto, dando lugar à ideia de um processo formativo, pedagógico, de aprendizagem e, acima de tudo, centrado no desempenho das organizações e não dos médicos tomados individualmente.

Verifica-se, em suma, que as respostas da MGF às lógicas de regulação externa configuram uma apropriação estratégica que, mais do que expressar uma simples colonização dos pressupostos managerialistas relativamente à profissão médica, é, 
acima de tudo, denotativa de lógicas mais complexas e compósitas de adoção destes novos imperativos no próprio modelo profissional desta especialidade (Exworthy, 2015), donde resulta que os profissionais não foram agentes passivos face às mudanças do contexto externo.

\section{Referências bibliográficas}

Abbot, Andrew (1988), The System of Professions. An Essay on the Division of Expert Labor, Chicago, The University of Chicago Press.

Armstrong, David (1979), "The emancipation of biographical medicine", Social Science \& Medicine, 13A, pp. 1-8.

Battista, Renaldo, Matthew Hodge, e Paolo Vineis (1995), “Medicine, practice and guidelines: the uneasy juncture of science and art", Journal of Clinical Epidemiology, 48, pp. 875-880.

Calnan, Michael e Jonathan Gabe (2009), “The reestratification of primary care in England? A sociological analysis", em Jonathan Gabe e Michael Calnan (orgs.), The New Sociology of Health Service, Londres, Routledge, pp. 56-78.

Carapinheiro, Graça (1991), "Médicos e representaç̃es da medicina: humanismo e tecnicismo nas práticas médicas hospitalares", Sociologia, Problemas e Práticas, 9, pp. 27-41.

Carapinheiro, Graça (1993), Saberes e Poderes no Hospital. Uma Sociologia dos Serviços Hospitalares, Porto, Edições Afrontamento ( $3^{\mathrm{a}}$ edição).

Carapinheiro, Graça (2006), "A saúde enquanto matéria política", em Graça Carapinheiro (org.), Sociologia da Saúde. Estudos e Perspectivas, Coimbra, Pé de Página, pp. 137-164.

Carneiro, António Vaz (2011), Oito Evidências Clínicas de 2010 Relevantes para os Cuidados Primários, Lisboa, CEMBE.

Castel, Patrick (2009), “What's behind a guideline? Authority, competition and collaboration in the French Oncology sector", Social Studies of Science, 39 (5), pp. 743-764.

Checkland, Kath, et al. (2008), "Biomedicine, holism and general practice: responses to the 2004 general practitioner contract", Sociology of Health \& Illness, 30 (5), pp. 788-803.

Correia, Tiago (2012), Medicina. O Agir Numa Saúde em Mudança, Lisboa, Mundos Sociais.

Exworthy, Mark (2015), “The iron cage and the gaze? Re-interpreting medical control in the English Health System", Professions \& Professionalism, 5 (1), pp. 1-14.

Freidson, Eliot (1988 [1970]), Profession of Medicine. A Study of the Sociology of Applied Knowledge, Chicago, The University of Chicago Press.

Geltzer, Anna (2009), “When the standards aren't standard: evidence-based medicine in the Russian context", Social Science \& Medicine, 6, pp. 526-532.

Greenhalgh, Trisha (2006), How to Read a Paper. The Basics of Evidence-Based Medicine, Malden, MA, Blackwell Publishing/BMJ Books.

Hodgetts, Katherine, Adam Elshaug, e Janett Hiller (2012), “What counts and how to count it: physician's constructions of evidence in a disinvestment context", Social Science $\mathcal{E}$ Medicine, 75 (12), pp. 2191-2199.

Jewson, Nicholas (1976), "The dDisappearence of the sick man from medical cosmology 1770-1870", Sociology, 10 (2), pp. 225-244. 
Johnson, Terence (1972), Professions and Power, Londres, Macmillan.

Jordão, José Guilherme (1995), A Medicina Geral e Familiar. Caracterização da Prática e Sua Influência no Ensino Pré-Graduado, Lisboa, Faculdade de Medicina da Universidade de Lisboa, dissertação de doutoramento em Medicina.

Knaapen, Loes (2013), "Being 'evidence-based' in the absence of evidence: the management of non-evidence in guideline development", Social Studies of Science, 43 (5), pp. 681-706.

Kuhlmann, Ellen (2006), Modernising Health Care. Reinventing Professions, the State and the Public, Bristol, Policy Press.

Larson, Magali (2013 [1977]), The Rise of Professionalism. Monopolies of Competence and Sheletered Markets, New Brunswick, NJ, Transaction Publishers.

Lupton, Deborah (1994), "The lay perspective on illness and disease”, em Medicine as Culture. Illness, Disease and the Body in Western Societies, Londres, Sage Publications, pp. $79-104$.

McDonald, Ruth, e Stephen Harrison (2004), “The micropolitics of clinical guidelines: an empirical study", Policy and Politics, 32, pp. 223-239.

MCSP - Missão para os Cuidados de Saúde Primários (2006), Linhas de Acção Prioritária para o Desenvolvimento dos Cuidados de Saúde Primários, Lisboa, MSCP.

Miguel, Luís Silva (2010), “Modelos de gestão nos Cuidados de Saúde Primários”, em Jorge Simões (coord.), 30 Anos do Serviço Nacional de Saúde. Um Percurso Comentado, Coimbra, Almedina, pp. 355-387.

Moreira, Tiago (2005), “Diversity in clinical guidelines: the role of repertoires of evaluation", Social Science \& Medicine, 60, pp. 1975-1985.

MS - Ministério da Saúde (2004), Plano Nacional de Saúde, 2004/2010. Mais Saúde para Todos, Lisboa, Direção-Geral de Saúde.

Pickard, Susan (2009), “The professionalization of general practicioners with a special interest: rationalization, restratification and governmentality", Sociology, 43 (2), pp. 250-267.

Porter, Roy (2006), “Medical Science”, em Roy Porter (org.), History of Medicine, Cambridge, Cambridge University Press, pp. 136-175.

Ramos, Vítor (1987), “O ressurgimento da Medicina Familiar”, Revista Crítica de Ciências Sociais, 23, pp. 157-168.

Raposo, Hélder (2014), Entre Padronização e Discricionariedade. Reconfigurações do Conhecimento Médico na Medicina Geral e Familiar, tese de doutoramento em Ciências Sociais, especialidade de Sociologia Geral, Lisboa, Instituto de Ciências Sociais da Universidade de Lisboa.

Sá, Armando Brito (2002), A Decisão em Medicina Geral e Familiar. Um Modelo de Decisão Clínica Tomando como Exemplo a Infecção Genital por Chlamydia trachomatas, Lisboa, Faculdade de Medicina da Universidade de Lisboa, dissertação de doutoramento em Medicina.

Serra, Helena (2008), Médicos e Poder. Transplantação Hepática e Tecnocracias, Coimbra, Almedina.

Silva, Mariana Vieira (2012), "Políticas públicas de saúde: tendências recentes", Sociologia, Problemas e Práticas, 69, pp. 121-128.

Starr, Paul (1982), The Social Transformation of American Medicine. The Rise of a Sovereign Profession and the Making of a Vast Industry, Nova Iorque, Basic Books. 
Teixeira, Lurdes (2012), A Reforma do Centro de Saúde. Percursos e Discursos, Lisboa, Editora Mundos Sociais.

Timmermans, Stefan (2005), “Scientific Medicine”, em Sal Restivo (org.), Science, Technology and Society, Oxford, Oxford University Press, pp. 323-327.

Timmermans, Stefan, e Marc Berg (2003), The Gold Standard. The Challenge of Evidence-Based Medicine and Standardization in Health Care, Filadélfia, Temple University Press.

Timmermans, Stefan, e Hyeyoung Oh (2010), “The continued social transformation of the medical profession", Journal of Health and Social Behavior, 51, pp. S94-S106.

Timmermans, Stefan,e Steven Epstein (2010), “A world of standards but not a standard world: toward a sociology of standard and standardization", Annual Review of Sociology, 36, pp. 69-89.

Vaz, António Faria (2012), “Normas de Orientação Clínica. Cuidados de Saúde Primários - ponto da situação", Encontro da Federação Nacional dos Médicos, Coimbra, 28 de janeiro de 2012.

Weisz, George (2003), "The emergence of medical specialization in the nineteenth century", Bulletin of the History of Medicine, 77, pp. 536-575.

Hélder Raposo. Professor adjunto na Escola Superior de Tecnologia da Saúde de Lisboa (ESTeSL-IPL), Departamento das Ciências Sociais e Humanas.

E-mail: helder.raposo@estesl.ipl.pt

Receção: 03 de maio de 2018 Aprovação: 24 de maio de 2018 